\title{
Dr. Michael W. Ogden, Recipient of the 2014 Tobacco Science Research Conference Lifetime Achievement Award
}

\author{
Laudatio to the award given by
}

Buddy G. Brown, B.S.

5714 Wanderlust Lane, Durham, NC 27712, USA

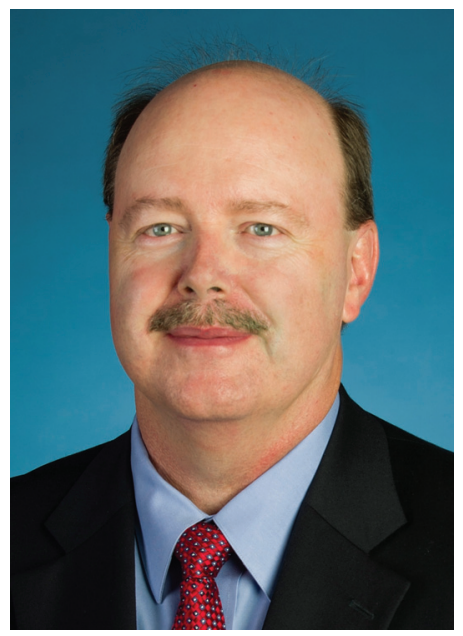

Michael W. ("Mike") Ogden, a native of Virginia, received B.S. degrees in both Chemistry and Applied Mathematics from Emory \& Henry College, and a Ph.D. in Analytical Chemistry from Virginia Tech. In 1985, he joined the Research \& Development Department of R.J. Reynolds Tobacco Company in Winston-Salem, North Carolina, as a research chemist. R.J. Reynolds is a subsidiary of Reynolds American Inc.

His initial work was focused on development of markers, methods, and measurements to determine the chemistry of, and exposure to environmental tobacco smoke (ETS). The work of him and his team led to the establishment of many official methods of analysis, including among AOAC, ASTM, CORESTA, EPA, and ISO. In recognition, Mike received the 1991 AOAC Associate Referee of the Year Award, the 1992 TSRC Distinguished Achievement in Tobacco Science Award, and the 2002 CORESTA Prize. Within R.J. Reynolds, Mike held various scientific and research management positions over 25 years. After rising to Principal Scientist in 1998, he became Director of Biological Chemistry in 2001 and Senior Director of Human Studies in 2006, reflecting an increased research interest in biochemistry, toxicology, and epidemiology. During this time, he led one of the company's first randomized controlled clinical trials to examine levels of biomarkers of exposure in smokers who switched to potentially reduced exposure products and was the first to investigate metabolomics in biofluids of smokers using various tobacco products.

Since 2009, Mike has been Senior Director of Regulatory Oversight at another Reynolds American subsidiary, RAI Services Company, where he is responsible for scientific and regulatory engagement for all Reynolds American tobacco operating companies.

Mike has been actively involved in TSRC and CORESTA over the past three decades. In TSRC, he has been member and chair of the Program Editorial Committee, member of the Analytical Methods Committee, and has been on the organizing committee of several conferences. In addition, he was a primary proponent and led the charge in 1998 for the name change of the Tobacco Chemists' Research Conference (TCRC) to the present Tobacco Science Research Conference (TSRC) in order to better reflect a multidisciplinary approach to tobacco research beyond chemistry (in vitro and in vivo toxicology, human studies, etc.).

In addition to active roles within various CORESTA Task Forces and Sub-Groups, Mike was a member of the Scientific Commission from 1996-2002. He led the 2002 CORESTA Congress organizing committee and has played determinant roles in moving CORESTA forward in looking at biological effects of tobacco products and in fulfilling its mission to promote international cooperation in scientific research relative to tobacco. He became R.J. Reynolds' representative on the CORESTA Board in 2004 and, since 
then, has served two terms each as CORESTA's VicePresident and President. He is widely regarded in CORESTA for his strategic views on driving change and transformation within the tobacco industry at a global level. For service to CORESTA, Mike has been awarded the CORESTA bronze, silver, and gold medals in 2000, 2006, and 2014, respectively.

Mike has been a member of ACS since 1984, AOAC since 1987, ASTM since 1994, Editorial Board member of Tobacco Science 1996-2004, Executive Board member and Treasurer of ANSI TAG ISO/TC 126 since 1997, Advisory Board member of Beiträge zur Tabakforschung International since 1998, and Adjunct Professor of Chemistry at Virginia Tech since 2006. He has authored or co-authored over 80 technical publications, more than 100 conference presentations, and holds 3 patents.

Significant mentors have been Ray Spell, Harold McNair, Alan Rodgman, and Charles Green.

Mike and his wife Diane reside in Winston-Salem and are parents of two sons, Eric and Robert.
Mike has a unique ability to challenge and critique research in an honest and non-threatening style. He is well-respected throughout the industry for his tremendous knowledge and his skill at relaying this knowledge in a thorough and understanding manner.

Because of his dedication and contributions to the tobacco industry over almost 30 years Dr. Michael W. Ogden is extremely deserving of the 2014 TSRC Lifetime Achievement Award.

Buddy G. Brown, B.S.

Master Scientist, RJRT Retired

5714 Wanderlust Lane

Durham, NC 27712, USA

E-mail:brownbg@nc.rr.com 